\title{
Schistosomiasis Epidemiology and Control: How Did We Get Here and Where Should We Go?
}

\author{
RF Sturrock \\ Department of Infectious and Tropical Diseases, London School of Hygiene and Tropical Medicine, Keppel \\ Street, London WC1E 7HT, UK
}

Although a disease of great antiquity, scientific studies of schistosomiasis began only 150 years ago. The complete life-cycle was not described until just before the First World War, making it possible at last to plan proper community control programmes. Inadequate tools prevented their effective implementation until well after the Second World War when new tools became available, thanks to the newly formed World Health Organization. Molluscicides spearheaded control programmes until the late 1970s but were then replaced by the newly developed, safe drugs still used today. Whatever the method used, the initial goal of eradication was, in the light of experience and cost, gradually replaced by less ambitious targets; first to stop transmission and then to reduce morbidity. The most successful programmes combined several methods to minimise reinfection after chemotherapy. Comparisons between different programmes are difficult without using appropriate, standardised diagnostic techniques and the correct epidemiological measurements. Some examples will be presented, mainly from our studies on Schistosoma mansoni in Kenya.

Drug resistance on a scale comparable with malaria has not occurred in schistosomiasis but the likely withdrawal of all drugs except praziquantel leaves its control extremely vulnerable to this potential problem. An effective, affordable vaccine for use in endemic countries is unlikely to be ready for at least 5 years, and developing strategies for its use could take a further decade or more, judging from experience with drugs and molluscicides. In the interim, by analogy with malaria, the most costeffective approach would the use of drugs combined with other methods to stop transmission, including molluscicides. The cost of molluscicides needs to be reduced and fears allayed about their supposedly adverse ecological effects.

Key words: schistosomiasis - epidemiology - control

(What follows is a an idiosyncratic view based on nearly 40 years experience of schistosomiasis research and control. The views are my own but I am indebted to those acknowledged below for unpublished Kenyan data used I have used in examples.)

Schistosomiasis is an ancient disease of man: eggs have been recovered from Egyptian and Chinese mummies several thousand years old (Nunn \& Tapp 2000). However, scientific studies of the disease did not start until the middle of the 19th century with independent reports, first by Japanese workers, who described the early, acute Katayama syndrome (Fuji 1847) and then by Bilharz (1852) who found distome trematodes in the urogenital blood vessels during post mortem examina-

E-mail: sturrock@tesco.net

Received 14 May 2001

Accepted 25 July 2001 tions of Egyptian corpses. Over 60 years later, just before the First World War, Japanese workers (Miyairi \& Suzuki 1914) finally incriminated amphibious, prosobranch snails of the genus $\mathrm{On}$ comelania as the intermediate host of the Oriental schistosome, Schistosoma japonicum, and Leiper (1915) showed that aquatic, pulmonate snails of the genera Bulinus and Biomphalaria transmitted $S$. haematobium and S. mansoni, respectively. Thus, the taxonomical problems about the genus Biomphalaria, that have so exercised Dr Lobato Paraense, were created by 19th century shell collectors and naturalists ignorant of its medical importance!

With the full description of the schistosome lifecycle, public health workers could at last contemplate community control programmes. It is, though, one thing to speculate on theoretical control measures to eradicate snails from water bodies or worms from people; to prevent either contamination of aquatic snail habitats by egg infested human excreta or human exposure to cercarial infested water; or even to develop a vaccine to stop schistosomula invading people (and all these ap- 
proaches were suggested at the time by 'arm-chair experts'!). Putting them into practice is quite another matter. To ensure the success of any intervention requires the means, the funds and the will, as well as sufficient knowledge of all aspects of the schistosome transmission cycle.

\section{EARLY CONTROL PROGRAMS AND THEIR LIMITATIONS}

In the initial absence of any antischistosomal drugs, early control efforts focussed on the elimination of snails. Periodic drying of Egyptian irrigation canals merely duplicated catastrophes which snails were already used to in their natural habitats. Snail numbers dropped briefly but the survivors soon replaced any losses. Transmission was, at best, merely interrupted. Chemical control was hampered because the water to be treated was that used by people for domestic and agricultural purposes. Copper sulphate was the only 'safe' chemical readily available. Highly effective in the laboratory, it was far less effective in the field, but remained in use well into the 1950s.

Educating rural populations to prevent human contamination of, and exposure to, potential transmission sites has little chance of success without provision of safe water supplies and acceptable means of excreta disposal. It was rapidly concluded in Egypt that such provisions and their maintenance would be impossibly expensive in rural areas. This remains the situation, today, in countries with endemic schistosomiasis (apart from the very few which have achieved political and economic stability so that everyone can afford to improve their living conditions). Greater progress was possible in stable urban centres where such measures were cost effective and had many other potential benefits.

At the end of the First World War, the chance discovery of the antischistosomal properties of Tartar Emetic against all three major schistosomes infecting humans raised hopes of therapeutic interventions using antimonial drugs (McDonagh 1918, Christopherson 1918). Long courses of painful injections and serious side effects meant that they were really suitable only for treating patients in hospital. When used in the 1920s for outpatients to try to prevent Egyptian labourers introducing $S$. haematobium during the construction of the new Sudanese irrigation schemes, mortality was estimated at 3 per 1,000 patients treated (Jordan 2000).

Between the two World Wars, community control of schistosomiasis was attempted in various places based mainly on the combined use of the two imperfect weapons available: copper sulphate and antimonial drugs, supplemented in some cases by provision of safe water and sanitation. Occasional successes were claimed in Egypt but followup studies showed them to be ephemeral as, for example, at the Dakhla Oasis (Khalil 1938). Far from decreasing, the number of people exposed to schistosomiasis was, if anything, increasing. Its distribution was spreading as the number of habitats available for the intermediate hosts was extended by water development projects such as dams, irrigation schemes, river navigation improvements and impedance of drainage associated with the growing construction of roads.

\section{DEVELOPMENT OF CONTROL AFTER WORLD WAR TWO}

The World Health Organisation, formed after the Second World War in 1948, found schistosomiasis control was little changed from that prevailing at the end of the First World War. Moreover, it promised to get worse when ambitious plans for water resource developments were eventually executed to increase the agricultural and industrial productivity of developing countries. These developments, besides extending the number and distribution of potential snail habitats, resulted in mass population movements and changed agricultural practices, all favouring the spread of schistosomiasis. At the time, few anticipated the human population explosion in the second half of the century which would greatly increase the number of people at risk. Accelerating migration from the countryside to the town threatened to overwhelm existing, aging water and sanitation systems, and to increase urban schistosomiasis in the periurban slums.

Compared with malaria, which WHO confidently (if, with hindsight, misguidedly) expected to eradicate quite easily because of the range of effective drugs and insecticides available, the schistosomiasis situation was very bleak. The main tools were toxic antimonial drugs and an ineffective molluscicide. WHO orchestrated a research programme by national, international and commercial organisations to remedy the lack of molluscicides and drugs.

\section{Snail control}

The first fruits of the WHO programme were molluscicides which became available in the mid 1950s and one of which, niclosamide, is still in use and effective today. For the next 25 years, community control of schistosomiasis was spearheaded by molluscicides in Africa, south west Asia and, to a lesser extent, the New World. Careful biological studies suggested an alternative approach to the control of Oriental schistosomiasis: Oncomelania populations are less resilient than Biomphalaria and Bulinus spp. to disturbance. Habitat modification was recommended as a potential control 
measure because it also improved rice production and this could, potentially, fund the elimination of snail habitats (Pesigan et al. 1958).

Initial hopes of eradicating aquatic snails with one or two molluscicide applications, especially from irrigation schemes, were soon dashed. Field studies on snail population dynamics were undertaken to improve the timing and efficacy of molluscicidal applications (Dazo et al. 1966) and were followed by field studies on transmission of the schistosomes. The seasonality of transmission was revealed in many, though not all, areas. Carefully timed mollusciciding was then able to minimise, if not stop, transmission in many places well into the 1980s (Sturrock et al. 1974). However, the effect on the human worm burden was slow (Jordan 1985). Interest in molluscicides began to wane when new drugs finally appeared and their decline was hastened by the sharp rise in the price of pesticides after the oil crisis in the 1970s, and by a growing (though largely unjustified) fear of adverse environmental effects. In some places they were completely abandoned.

\section{Drug control}

Development of drugs took much longer than that of molluscicides. By the early 1970s, metrifonate was established for use against $S$. haematobium, although the need for three fortnightly treatments caused logistic problems for community use. Fears for its safety prevented the widespread acceptance of hycanthone, the first single-dose drug effective against $S$. mansoni and, possibly, S. haematobium, but a similar drug, oxaminiquine, was released for community use against $S$. mansoni in the 1970 s. The real turning point was the arrival in the early 1980s of praziquantel, a safe, effective, single-dose drug active for all schistosomes and many other human and veterinary helminths, besides (WHO 1985). It promised to revolutionise community chemotherapy against schistosomiasis, although it was initially too expensive for widespread use. Its price has at last dropped radically and it is now the major weapon for community control of schistosomiasis.

New drugs revived hopes of eradicating schistosomes directly by treating people. Single-dose treatment programmes certainly had dramatic results, but transmission persisted and reinfection invariably occurred. Experience showed that repeated treatments were essential to maintain initial gains. As long as praziquantel remained expensive, eradication seemed impossible: morbidity control became a more realistic objective. The most successful control programmes have been those that included some method of curbing transmission, including mollusciciding, even at a reduced level
(Webbe \& El Hak 1990). Transmission control delays reinfection and extends the period between treatments, thereby reducing drug delivery costs.

\section{DIAGNOSIS AND EPIDEMIOLOGY}

Identifying human schistosome infections is crucial at all stages of schistosome control programmes, and for comparing control programmes. Diagnostic methods are the key to such comparisons and, not surprisingly, a great many tests have been developed over the years. Complete standardisation will never be achieved but, if comparisons are to be justified, the techniques used must be clearly described and their limitations appreciated. Some methods most commonly used are summarised below.

\section{Parasitological diagnosis}

Adult worms lie hidden in the blood system and parasitological diagnosis is therefore indirect evidence of their presence within a patient, relying on the detection of eggs in urine or faecal samples. It is, though, absolutely specific because an egg is direct proof of infection. (Some caution is needed for atypical eggs, e.g., S. bovis eggs in an infected cow liver can pass through the human bowel to give the spurious appearance of infection (Kinoti $\&$ Mumo 1988).) The techniques are relatively simple and cheap but technicians require proper training and access to a microscope. The main limitations are that the techniques are slow, labour intensive and aesthetically unpleasant.

Today, the most widely used methods are the Kato thick smear (Katz et al. 1972) and the Nuclepore filtration techniques for faecal and urine examination, respectively (Feldmeier 1993). A standard, 50 $\mathrm{mg}$ Kato thick smear has a detection threshold of 20 eggs per gram (epg) of faeces (1 egg per slide): smaller, quick, Kato smears have higher thresholds (e.g., 50 epg for a $20 \mathrm{mg}$ smear smear). Nuclepore filtration is conventionally used to examine $10 \mathrm{ml}$ of urine collected between 11.00 and $14.00 \mathrm{~h}$ at the peak of the diurnal egg count cycle. There is considerable day to day variation in egg counts, both in urine and faecal samples and there is little point trying to estimate absolute worm burden from egg counts for an individual because there are so many possible sources of variation. However, classification of egg counts from a community on a relatively coarse scale will detect overall trends after a control intervention: in this context, egg counts are a quantitative, or at least a semi-quantitative, measurement of infection - a few eggs indicating a few worms and a lot of eggs, a lot of worms. The main deficiency of egg counts is missing very light infections at or below the threshold of detection. For quantitative purposes, examining duplicate 
samples on three or more days increases the chance of finding eggs, but at increased costs in time and labour (Engels 1997).

\section{Immunodiagnostic methods}

Immunodiagnosis of schistosomiasis relies mainly on antibodies to detect antigens and vice versa. In some, though not all, instances, their levels in man are more stable than those of egg counts. Invasive skin tests have been abandoned and most tests are now performed on serum or plasma samples from finger prick or venous blood. Even these procedures are considered intrusive and attention is turning to other body fluids such as urine, milk, and saliva or other oral exudates (Garcia Santos et al. 2000).

Antibody detection tests provide only indirect proof of exposure because they are molecules produced by the host's immune response to the parasite. Prepatent and early infections may not have stimulated a detectable antibody response, resulting in false negative tests if the wrong antigen is used. Positive tests do not necessarily denote an active (living) infection. Antibody tests are also prone to cross reactions with other infections (especially tissue dwelling parasites) which diminishes their sensitivity (for detecting infected cases) and specificity (for detecting normal, uninfected people). However, improved reagents provided by molecular biological techniques have revived interest in antibody detection, particularly for specific isotypes and sub-classes associated with different stages of infection. Imperfect correlations between antibody levels and egg counts may give some evidence of the intensity of infection in communities. Positive antibody tests are usually, at best, qualitative evidence of past or present exposure to infection.

Antigen tests, by definition, detect molecules produced by the parasite and are therefore just as much direct proof of infection as finding eggs. Antigen levels are often significantly lower than those of antibodies, but, theoretically, are directly related to the number of worms present. Continuously improving techniques now allow detection of very low antigen levels. Levels tend to be more stable than egg counts but the relationship between egg counts and antigen levels is not always perfect. Although antigen tests often confirm suspected light infections with sparse eggs, negative antigen tests still occur in subjects passing eggs. Despite claims to the contrary, egg counts remain the gold standard for diagnosis (Hagan et al. 1998).

At first, both antibody and antigen tests required access to dedicated laboratories to process samples. Recently, simple dip-stick/card tests have been developed for field use (Van Etten et al. 1994) but none are available commercially and they will have to be cheap enough for routine use.

\section{Indirect diagnostic methods}

The association of $S$. haematobium with haematuria is well known, especially among children before puberty, although it is not always predictable. In endemic areas, visual inspection of daily urine samples over 3- to 5-days can be a simple, cheap way to detect most infections in schoolchildren and is of use in control programmes, with or without the additional refinement (and cost) of dipsticks to detect blood and/or protein in the urine (Savioli et al. 1990). The association of signs and symptoms is less clear cut for $S$. mansoni and $S$. japonicum: other causes must be ruled out, especially for diarrhoea and bloody diarrhoea. Hepatosplenomegaly and splenomegaly, detected clinically by palpation, often occur in high transmission endemic areas, and indicate significant schistosomal pathology. Subjective, between-observer variations in these clinical measurement remain a problem despite attempts at standardisation using defined axes for reporting results (DoehringSchwerdtfeger et al. 1995).

The development in the last 10 to 15 years of portable ultrasound equipment suitable for field use has been a significant advance (Hatz 1993). The equipment is not cheap, properly trained operators are required and the technique does not detect worms or eggs directly. Its main contribution is the accurate measurement of various organs and in the visualisation of lesions characteristic of schistosomiasis in either the hepatic portal plexus, including the liver and spleen, or the urogenital system. There remain, though, problems in interpreting the results from different areas. Suggested standardised measurements have not proved universally applicable, hampering comparisons of between areas. Ultrasound is, nevertheless, useful in characterising the clinical situation within areas and, potentially, for monitoring the effects of control interventions.

\section{EPIDEMIOLOGICAL MEASUREMENTS IN SCHIS- TOSOMIASIS}

\section{Commonly used measurements}

The human measurements most widely used in schistosomiasis epidemiology are based on the prevalence of active infections in the community. Prevalence classifies subjects as positive or negative for (usually) the presence of eggs, and is recorded as the proportion or percentage positive. Cure rate $(\mathrm{CR})$ is the percentage of patients who stop passing eggs within 5 or 6 weeks after treatment). Incidence records changes from negative to positive over a predetermined time period. All three measurements are qualitative, binary variables and 
none indicates the intensity of infections - an important consideration for long-lived, helminths which do not multiply in the host and whose numbers increase only after repeated exposures over time.

In contrast, intensity is a continuous, quantitative variable expressed as epg for faeces or as eggs/ $10 \mathrm{ml}$ for urine. Within a community, the individual egg counts are distributed asymmetrically with most of the eggs passed by $10 \%-20 \%$ of the subjects and the rest passing few or no eggs. Egg counts are conventionally transformed to $\log (\mathrm{x}+1)$ to include zero counts and normalise their distribution for statistical analysis, but reported in epg as the geometric mean $(\mathrm{GM}=\operatorname{antilog}[\{\Sigma \log (\mathrm{x}+1)\} / \mathrm{n}]-1$, where $\mathrm{n}=$ the number of subjects in any age, sex, age-sex or other group). Despite their admitted shortcomings, egg counts reflect the number of worms present at a specific time. They also show significant changes when, for example, children acquire increasing worm loads due to cumulative exposure over time, or worm numbers drop after successful treatment. If egg counts are near the threshold of egg detection, especially after treatment, sufficient replicate samples must be examined to avoid misclassifying light infections as negative.

In practice, the easiest measurements to obtain and the most widely used are the qualitative indicators (prevalence, cure rate and annual incidence) but they are relatively insensitive and reveal only gross changes. The most informative is annual incidence (the rate of transmission in an accurately defined cohort of uninfected subjects) although it may be hard to obtain in high prevalence areas where uninfected subjects may confined to atypical age groups such as very young children. Quantitative measurements of intensity, though more difficult to obtain, are more sensitive to change, especially repeated measurements on a cohort.

Although fundamentally different measurements, prevalence and intensity are related: prevalence rises with increasing intensity to an upper limit of $100 \%$ but intensity has no theoretical upper limit. It is now accepted (WHO 1998) that rising intensity is accompanied by an increased risk of developing morbidity and disease (pathology of the urogenital tract; hepatomegaly and hepatosplenomegaly). However, severe pathology can occur in light infections and does not develop in all heavy infections.

\section{Planning control programmes}

When snail control for schistosomiasis began in earnest in the 1950s and 1960s, the tacit aim was to eradicate the snails and hence, ultimately, the parasites; a process that might take one or more decades. Only qualitative egg counting techniques were available and success, if any, was judged primarily by reductions in prevalence (and incidence) of schistosomiasis in human populations. Twenty years later, when effective drugs came into use, the prevailing view was that they would succeed, where molluscicides had failed, in eradicating schistosomiasis by attacking the parasites directly. Assessment was still based mostly on qualitative criteria although quantitative egg counts were available by then. Rapid and dramatic prevalence drops after chemotherapy and quantitative measurements, if used, confirmed that drugs had more rapid effects than snail control (Cook et al. 1977).

Only gradually was it realised that it would be no easier to eradicate worms than snails. Just as the goal of snail control had shifted from eradication to the management of snail populations to suppress transmission, so, too, did the goal of chemotherapy change; from eradicating worms to suppressing their numbers to a level where they would no longer be of public health significance in the population (WHO 1985). Reducing the overall community worm burden should reduce the numbers of heavily infected people likely to develop disease.

To select the most appropriate control strategy for an area required some framework (WHO 1993). One such was based on a combination of ageprevalence and age-intensity curves (Fig. 1). Although there are differences in detail between the different human schistosomes, a generalised picture shows that overall prevalence rises to a peak in school children in the second decade of life before dropping to a somewhat lower level in older age groups (Ross et al. 2000). Plotting prevalence

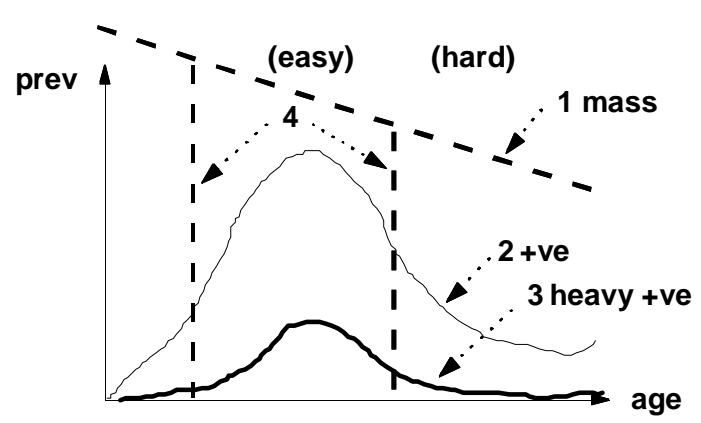

Fig. 1: diagrammatic representation of schistosomiasis ageprevalence curves to indicate various chemotherapy control strategies: 1. mass treatment of entire community without diagnosis (thick broken slope); 2. treatment targeted at all subjects diagnosed positive (upper thin-lined curve); 3. selective treatment targeted at people diagnosed as heavily infected (lower thick-lined curve; and 4. selective treatment targeted at school children (vertical thick broken lines) using 1, 2 or 3 as appropriate. 
of heavy infections ( $>400 \mathrm{epg}$ or $>1000 \mathrm{epg}$ for intestinal schistosomiasis; $>50$ or $>200 \mathrm{eggs} / 10 \mathrm{ml}$ for urinary schistosomiasis) gives a similar curve below that of total prevalence in each age group. The proportion of heavy infections is greatest at, or immediately after, the overall prevalence peak in school children. In older age groups, heavy infections are relatively lower than the total prevalence. This figure suggests several control strategies.

The simplest approach (Fig. 1.1) is mass chemotherapy, treating everybody in a known, endemic community with a curative dose of praziquantel. This was impossible in most endemic areas, if only because of the high cost of praziquantel at the time. Alternatives included targeted chemotherapy (Fig. 1.2), treating only infected subjects after examining everyone in the community to diagnose those infected; selective, targeted chemotherapy (Fig. 1.3), treating only those subjects with heavy infections (also needing diagnosis); and selective, targeted chemotherapy (Fig. 1.4), treating subjects in defined, high-risk groups (e.g. school children), with mass treatment (or targeted or selective, targeted chemotherapy with diagnosis).

Other factors affect the choice of strategy including the overall prevalence and intensity in a community, the nature and accessibility of its members, the proportion of the children who regularly attend school, where transmission occurs and if it is seasonal (and, if so, if it varies in intensity from year to year). At least one national programme (Brazil) followed these principles (Almeida Machado 1980).

\section{Evaluation of control programmes}

Snail control aimed to stop transmission. It had no immediate effect on the existing worm population in people and cure rates were irrelevant because of the long life-span of adult schistosomes. Overall prevalence remained unchanged for several years until worms died. A downward shift in the elevation of age-prevalence curves confirmed reduction in transmission and changes in the annual incidence were a more sensitive, qualitative indicator of success but took just as long to obtain. In contrast, repeated, quantitative measurement of intensity revealed changes over a year or even a single transmission season (Jordan 1985). Qualitative incidence (where possible) and quantitative measurements are appropriate for other measures for transmission control such as water supplies, sanitation and public health education.

Drugs kill the adult schistosomes but even praziquantel fails to kill every worm in every patient. Anyone passing a single egg after treatment is considered positive and, thus, a treatment failure, so the cure rate for a community is a poor measure of the effect of chemotherapy. Nor is prevalence much better. The percentage reduction (PR) in GM egg output is much more sensitive. For epi-

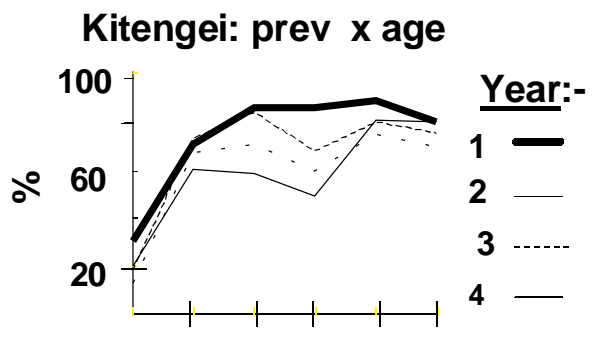

Age Group

\section{Kitengei: GM by age}

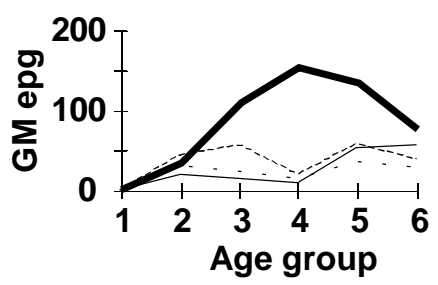

\section{Matithini: prev $x$ age}

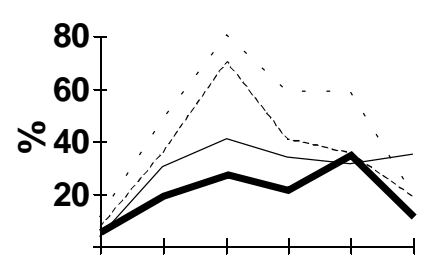

Age group

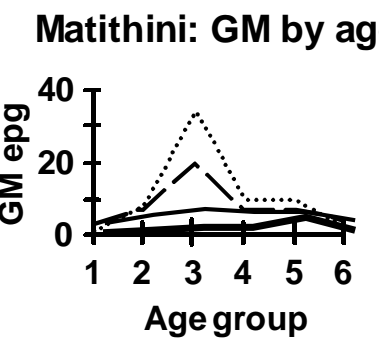

Fig. 2: age prevalence and intensity profiles from 1989 to 1992 (years 1 to 4) in two Kenyan communities: Kitengei, where school children were treated annually after the 1989 survey for Schistosoma mansoni; and Matathini, which received no systematic treatment in this period. (Age groups 1-6 were: 0-4, 5-8, 9-12, 13-20, 21-40 and over 40 years old respectively at start of study). 
demiological studies, the PR should be calculated for ALL subjects, uninfected and infected, before and after treatment. It is sometimes calculated only for patients who are not cured (Stelma et al. 1995). This may be of clinical interest to assess the risk of residual infections causing subsequent morbidity, but it is not strictly an epidemiological measurement reflecting events in the community as a whole.

EPIDEMIOLOGICAL MEASUREMENTS IN
SCHISTOSOMIASIS: EXAMPLES FROM KENYA

The following examples are drawn from a series of studies on the control of $S$. mansoni in Kenya over the last two decades to illustrate the use of these epidemiological measurements and their were interpretation.

\section{Prevalence, intensity, cure rates and percentage egg count reduction}

Table I shows data from three different communities in the Machakos and Makueni Districts of Kenya. Surveys in each community were performed on 500 to 600 individuals who provided faecal samples on three different days. Two Kato smears were examined from each sample (6 smears in total for each individual). All infected subjects were then treated with praziquantel $(40 \mathrm{mg} / \mathrm{kg})$ and the effect assessed three months later. (A five or six week follow up, before worms acquired after treatment could have begun producing eggs, would have been better but three months was used for logistical reasons). Contemporary data from Senegal (Stelma et al. 1995) are shown for comparison.

There was a direct correlation between pretreatment prevalence and intensity. Both were inversely related to cure rate (except the lowest Kenyan prevalence - a common discrepancy because the low prevalences include more light infections likely to be misclassified as normal, even with three faecal samples). Although the cure rates seemed disappointingly low ( $41 \%$ at best), the reduction in egg output (intensity) was over $80 \%$ in all cases. The Senegal result was an under estimate, based on treatment failures alone, but was the evidence for the 'unexpected failure of praziquantel' against $S$. mansoni (Anon 1992), raising fears of drug resistance, subsequently allayed by retreatment studies (Picquet et al. 1998) and attributed to the high infection intensities (De Vlas et al.1998).

\section{Age-prevalence and age-intensity for monitoring the effect of chemotherapy}

Figure 2 shows data from two Kenyan communities from 1989 to 1992 . The first, Kitengei, was in Makueni District (formerly part of Machakos District) about $200 \mathrm{~km}$ south east of Nairobi in an area of intense S. mansoni transmission; the second, Matathini, also in Machakos District about $100 \mathrm{~km}$ east of Nairobi, was in an area of moderate transmission. Kitengei had received no systematic treatment before late 1989 when annual treatment for three years began for all school children found infected at annual surveys. At Matathini, all infected subjects had been treated with praziquantel in 1988, but received no further treatment until the study ended and all infected subjects in both communities were offered treatment.

The Kitengei community before treatment had a typical, convex, age-prevalence curve, peaking at nearly $100 \%$ in the $13-20$ year olds. The first treatment markedly reduced prevalence and initial gains were maintained by the third treatment after a set back in the second year. The effect was greatest in children over 12 years of age though their prevalence still exceeded $50 \%$. Age-intensity profiles revealed a more encouraging picture: a $<90 \%$ drop achieved initially in all target groups was maintained by subsequent treatments, despite a slight resurgence in the second year. A 50\% reduction in intensity among untreated adults over the three year period was an added bonus. Both prevalence and intensity data suggest an especially intense transmission season in year 2 .

At Matathini, the atypical starting age prevalence and intensity curves reflect treatment in 1998. The typical teenage prevalence peak was firmly reestablished within three years although intensity

TABLE I

Changes in prevalence and intensity of Schistosoma mansoni in three Kenyan communities and a Senegalese community after treatment with praziquantel

\begin{tabular}{lcccccc}
\hline & & \multicolumn{2}{c}{ Pretreatment } & & \multicolumn{2}{c}{3 months after treatment } \\
\cline { 3 - 4 } Group & $\mathrm{n}$ & & \% prevalence & GM epg & & \% cure rate $\%$ egg reduction \\
\hline Kenya 1 & $\sim 550$ & $82.3 \%$ & 32 & & $20.7 \%$ & $84 \%$ \\
Kenya 2 & $\sim 550$ & $93.3 \%$ & 198 & & $40.6 \%$ & $98 \%$ \\
Kenya 3 & $\sim 550$ & $95.8 \%$ & 440 & & $18.7 \%$ & $94 \%$ \\
Senegal $^{a}$ & 298 & $100 \%$ & 713 & & $18 \%$ & $86 \%$ \\
\hline
\end{tabular}

a: Stelma et al. (1995) 
rose less rapidly. Both prevalence and intensity suggested especially intense transmission in the second year, as at Kitengei.

\section{Effect of chemotherapy on clinical morbidity}

Repeated treatment at Kitengei successfully reduced the intensity of $S$. mansoni infections in the target groups, but did it affect morbidity? Table II summarises findings from a series of clinical surveys performed at Kitengei during and after the chemotherapy study. At each survey, subjects were examined by the same clinical observers in a standardised manner for enlarged spleens and livers. Epidemic malaria occurs in this area and the convention used by Fulford et al. (1996) was adopted to differentiate between its effect (splenomegaly alone) and that of S. mansoni (hepatomegaly and hepatosplenomegaly).

Splenomegaly was low $(<6 \%)$ and steady until a sharp rise in a malaria epidemic during the last survey caused a significant rising trend over time. In contrast, the prevalence of hepatomegaly and hepatosplenomegaly declined steadily and significantly during and beyond the treatment programme. Annual praziquantel treatment had a beneficial effect on S. mansoni pathology, even though transmission continued but severe cases remained, though far less common than before.

\section{Measurement and control of transmission in snails in Kenya}

Transmission of S. mansoni in the Machakos/ Makueni Districts of Kenya - So far, the Kenyan examples have focussed on measuring the effect of chemotherapy on S. mansoni infections and their clinical sequelae in people. Snails have been ignored although they are essential for transmission. In this part of Kenya, S. mansoni is transmitted by B. pfeifferi, mainly in small streams and rivers where human contact is considerable. The snails originate from colonies in pools and marshy seepages at the head waters of the Athi River. In favourable conditions, they spill into the tributaries, forming colonies where snails become abundant and widespread. However, these colonies are washed completely away by heavy rains (Sturrock et al. 1994). As rainfall is seasonal in Kenya, there are corresponding fluctuations in snail numbers within years. There are also marked variations between years related to annual rainfall.

Transmission studies related to the 1989-1992 praziquantel trial - Representative sites were sampled fortnightly to monitor $S$. mansoni transmission by $B$. pfeifferi. Two crude indices were used to compare areas for a given year; the abundance of snails and the $S$. mansoni infection rate. Abundance is the geometric mean number of snails per sampling site per year. The infection rate is the percentage of all snails collected shedding schistosome cercariae.

At Kitengei, the abundance of B. pfeifferi for the four years from 1989 to 1992 was 689, 2573, 1826 and 653 snails per site, respectively. At Matathini, the equivalent figures were 376, 259, 461 and 156. Despite greater variability between years, snails were four to five times more abundant at Kitengei. The corresponding $S$. mansoni infection rates were $1.3 \%, 5.7 \%, 8.6 \%$ and $1.5 \%$ at Kitengei, and 9.2\%, $0.7 \% .4 .4 \%$ and $0.2 \%$ at Matathini, showing consistently higher infection rates at Kitengei, apart from 1989.

The snail and parasitological data both indicate low transmission at Kitengei in years 1 after chemotherapy began, increasing in year 2 and 3 when further treatments just about maintained the reductions in prevalence and intensity achieved during unusually low transmission in the first year. Transmission at Matathini, although lower than at Kitengei, was sufficient to allow steady reinfection in the absence of chemotherapy.

Attempts to contain S. mansoni transmission We were interested in studying whether the regression in pathology indicated in Table II would continue in the absence of reinfection. Studies such as those already described showed that repeated

TABLE II

Changes in prevalence of splenomegaly and combined hepatomegaly and hepatosplenomegaly in a Kenyan community during a programme of annual treatment of Schistosoma mansoni cases with praziquantel

\begin{tabular}{lcccc}
\hline Year & $\mathrm{n}$ & \% normal & $\begin{array}{c}\text { \% splenomegaly } \\
\text { (malaria) }\end{array}$ & $\begin{array}{c}\text { \% hepatosplenomegaly } \\
(\text { S. mansoni) }\end{array}$ \\
\hline 1989 & 598 & $71.4 \%$ & $3.8 \%$ & $24.7 \%$ \\
$1990 \mathrm{a}$ & 557 & $79.5 \%$ & $5.7 \%$ & $14.8 \%$ \\
$1990 \mathrm{~b}$ & 591 & $84.9 \%$ & $3.6 \%$ & $11.5 \%$ \\
1991 & 552 & $88.2 \%$ & $2.4 \%$ & $9.4 \%$ \\
1992 & 575 & $88 \%$ & $5.2 \%$ & $6.8 \%$ \\
1993 & 581 & $89.5 \%$ & $5.5 \%$ & $5 \%$ \\
1995 & 569 & $82.4 \%$ & $14.1 \%$ & $3.5 \%$ \\
\hline
\end{tabular}


chemotherapy alone could prevent the more serious consequences of $S$. mansoni infection but reinfection was inevitable if transmission continued. Considerable information acquired by earlier studies (Sturrock et al. 1994) showed the instability of stream snail colonies related to rainfall and, hence, the seasonality of transmission. We were already routinely giving chemotherapy between transmission seasons to avoid rapid reinfection but predicting $S$. mansoni transmission is no more accurate than weather forecasting. Could we render streams inimical to snails during transmission seasons? Mollusciciding seemed to be the answer.

Regular surveillance was started to detect snails invading streams cleared by the last rains. Any colonies found were treated focally with hand sprayers to apply molluscicide (niclosamide) according to the maker's recommendation. This action gave good control until the critical period before the onset of the next rains when rising temperatures and gentle flows favoured rapid growth of aquatic flora, increased the number of potential snail habitats and accelerated both the growth of the snail colonies and the development of the $S$. mansoni in the snails. At such times, the entire stream was treated with $8 \mathrm{mg} . \mathrm{h}^{-\mathrm{l}^{-1}}$ of niclosamide from an upstream, continuous-flow dispenser, supplemented by hand spraying of overgrown stream margins to boost the chemical concentration in areas most favoured by snails.

Table III summarises snail records for six years from two, adjacent tributaries of the Athi River, Makueni District. Mollusciciding of one stream began in 1995. Rainfall was measured near this stream and varied considerably from year to year. In the wettest (El Nino) year in 1997/1998, most of the $1430 \mathrm{~mm}$ fell as widespread rainfall affecting both tributaries between mid-December and midJanuary. In other years, localised storms affected one area more than the other, accounting for differences between the two areas before mollusciciding began. Thereafter, snail populations in the untreated area were fairly stable except in the El Nino year and $S$. mansoni infection rates were always in the range of 1 to $3 \%$. In the treated area, mollusciciding took time to have an effect but infected snails, though occasionally found, were much scarcer than in the untreated area. More important, snails, including infected snails, were confined to the upper reaches of the stream, well away from the study populations. Human data have yet to be fully analysed, but preliminary indications are that transmission has been held to an extremely low level.

\section{THE NEED FOR TRANSMISSION CONTROL}

Our experience in Kenya is matched by similar studies in Africa and elsewhere which all agree that drugs alone, although they will have public health benefits in reducing the pathological consequences of infection, will not eliminate transmission of schistosomiasis. Retreatment is essential to maintain initial reductions of prevalence and intensity.

The good news is that the price of praziquantel has dropped sharply in recent years. There has been an epidemic of mass treatment campaigns but these are mostly of short term, even those incorporating retreatment. The bad news is that these programmes will not stop transmission: when they end, prevalence, intensity and, eventually, pathology will rise again (Chen \& Feng 1999). Decision makers will, by then, be unwilling to spend more on what they will perceive as an ineffective control measure. Worse still is that the alternative drugs, metrifonate for S. haematobium and oxamniquine for $S$. mansoni, are now effectively unobtainable (Hagan et al. 2000) and we will be back to square one if resistance to praziquantel ever becomes a reality. Worse still, commercial companies have abandoned research on developing new drugs. Like WHO 50 years ago, we would have no effective drug although there would still be an effective molluscicide.

I must stress that I do not see molluscicides as a universal panacea for schistosomiasis control. Despite a recent revival of interest in plant molluscicides there is little evidence that they can be produced in sufficient amounts for use in a routine control programme of any size. The only tried and tested,commercially-produced molluscicide is niclosamide. Of course, there are many situations where its use is inappropriate. But why is it not more widely used where it is appropriate? An obvious reason is its high cost. For other tropical parasites, international agencies have successfully

\section{TABLE III}

Snail data for six years from two tributaries of the Athi River, Makueni District, Kenya before and after introducing mollusciciding to suppress the transmission of Schistosoma mansoni

\begin{tabular}{lccccc}
\hline & \multicolumn{8}{c}{$\begin{array}{c}\text { Mean no. of snails/site } \\
(\% \text { S. mansoni +ve) }\end{array}$} \\
\cline { 3 - 6 } Year & $\begin{array}{c}\text { Rainfall } \\
(\mathrm{mm})\end{array}$ & $\begin{array}{r}\text { Treated area } \\
(17 \text { sites })\end{array}$ & $\begin{array}{c}\text { Untreated area } \\
(10 \text { sites })\end{array}$ \\
\hline $1993 / 94$ & 536 & 2268 & $(4.1 \%)$ & 387 & $(2.3 \%)$ \\
$1994 / 95$ & 850 & 25 & $(0.1 \%)$ & 991 & $(2.8 \%)$ \\
& \multicolumn{7}{c}{ (Start of mollusciciding) } \\
$1995 / 96$ & 782 & 225 & $(2 \%)$ \\
$1996 / 97$ & 316 & 64 & $(0.4 \%)$ & 702 & $(2.2 \%)$ \\
$1997 / 98$ & 1430 & 4 & $(0 \%)$ & 282 & $(1.2 \%)$ \\
$1998 / 99$ & 569 & 67 & $(0.9 \%)$ & 549 & $(2.8 \%)$ \\
\hline
\end{tabular}


negotiated the provision of cheap or even free drugs to countries which could not otherwise afford them. Why not do the same for niclosamide? A second reason lies in fears that niclosamide is dangerous, if not for man, then for the environment, despite extensive evidence to the contrary (Webbe 1987).

If not molluscicides, what alternative means of transmission control remain? Provision of safe water supplies and sanitation is a council of perfection beyond the financial resources of most countries with endemic schistosomiasis. Yet without them, what hope has any public health education campaign? People can not change their behaviour without the means of doing so. Even if these facilities were available, natural water bodies in hot climates would remain magnets for children to perpetuate schistosomiasis transmission.

There is one other hope - a vaccine to reduce egg output if not to prevent infection. For 30 years I have repeatedly been told that there will be a one within five years, a promise that has yet to be fulfilled, though I am assured that things are changing. Even if a vaccine is successfully tested soon, it will take many years to bring it into widespread use and it will be no easier or cheaper than molluscicides or drugs, judged by past experience.

What can we do in the interim? There seems little prospect of a dramatic upturn in the world economy, sufficient to allow endemic countries to raise the living standards of their people enough to affect schistosomiasis transmission. It seems we must rely on repeated praziquantel treatments, ensuring that its quality is not sub standard and pray that significant resistance does not develop (WHO 1998). On which sombre note I will close!

\section{ACKNOWLEDGEMENTS}

To the following who all contributed to the collection of the unpublished data used as examples in this paper: Drs JH Ouma, HC Kariuki, FW Thiongo and Mr J Kioko, DVBD, MOH, Nairobi, Kenya; Drs D Koech, RK Gachuhi, G Mbugua and J Mwatha of KEMRI, Nairobi, Kenya; Professor AE Butterworth and Drs AJC Fulford and DW Dunne, University of Cambridge, UK; and Dr RK Klumpp, USA. We are all indebted to the DVBD and KEMRI technical staff for many years of field and laboratory work and, above all, to the communities in Machakos and Makueni Districts where we do our field studies.

\section{REFERENCES}

Almeida Machado P 1980. The Brazilian programme for schistosomiasis control, 1975-1979. Am J Trop Med Hyg 31: 76-86.

ANON 1992. Praziquantel shows unexpected failure in recent schistosomiasis outbreak. TDR News 41: 1-2.

Bilharz TM 1852. Fernere Beobachtungen uber das die Pfortader des Menschen bewohnende Distomum haematobium und sein verhaltniss zu gewissen patalogischen Bildungen aus brieflichen Mitheilungen an Professor v. Siebold vom 29 Marz 1852. Zeitschr Wschft Zool, Leipzig 4: 72-76.

Chen MG, Feng Z 1999. Schistosomiasis control in the People's Republic of China. Parasitol Int 48: 11-19.

Christopherson JB 1918. The successful use of antimony in bilharziasis administered as intravenous injections of antimonium tartrate, tartar emetic. Lancet ii: $325-327$.

Cook JA, Jordan P, Bartholemew RK 1977. Control of Schistosoma mansoni transmission by chemotherapy in St Lucia. 1. Results in man. Am J Trop Med Hyg 26: 887-893.

Dazo BC, Hairston NG, Dawood IK 1966.The ecology of Bulinus truncatus and Biomphalaria alexandrina and its implications for the control of bilharziasis in the Egypt-49 Project area. Bull WHO 35: 339-356.

De Vlas SJ, Engels D, Mbaye A, Gryseels B 1998. Low praziquantel cure rates in Senegal can be explained from high intensities. In The Final SRP International Conference on Schistosomiasis, March 1998, MOH, Cairo, p. 211.

Doehring-Schwerdtfeger E, Kardoff R 1995. Ultrasonography in schistosomiasis in Africa. Mem Inst Oswaldo Cruz 90: 141-145.

Engels D 1997. The Operational Diagnosis of Human Schistosoma mansoni Infection. Thesis, Department of Parasitology, Leiden University, 165 pp.

Feldmeier H 1993. Diagnosis. In P Jordan, G Webbe, RF Sturrock, Human Schistosomiasis, CAB International, Wallingford, p. 271-303.

Fuji 1847. Katayama disease, Katayamaki. Chugai Iji Shimpo 691: 55-56.

Fulford AJC, Mbugua GC, Ouma JH, Kariuki HC, Sturrock RF, Butterworth AE 1996. Differences in the rate of hepatosplenomegaly due to Schistosoma mansoni infection between two areas in Machakos District, Kenya. Trans $R$ Soc Trop Med Hyg 85: 481- 488.

Garcia Santos MMA, Garcia TC, Orsini M, Disch J, Katz N, Rabello A 2000. Oral fluids for the immunodiagnosis of Schistosoma mansoni infections. Am J Trop Med Hyg 94: 289-292.

Hagan P, Doenhoff MA, Wilson RA, Al-Sherbiny M, Berquist R 2000. Schistosomiasis: a response to a Devil's Advocate's view. Parasitol Today 16: $322-$ 323.

Hagan P, El Meleigy M, Traore M 1998. Schistosomiasis research: the end of the beginning. Parasitol Today 14: 392-394.

Hatz C 1993. Use of ultrasound. In P Jordan, G Webbe, RF Sturrock, Human Schistosomiasis, CAB International, Wallingford, p. 305-329.

Jordan P 1985. Schistosomiasis. The St Lucia Project, Cambridge University Press, Cambridge. 442 pp.

Jordan P 2000. From Katayama to the Dakhla Oasis the beginning of epidemiology and control of bilharzia. Acta Trop 77: 9-40.

Katz NK, Chaves A, Pellegrino J 1972. A simple device for quantitative stool thick-smear in schistosomiasis mansoni. Rev Inst Med São Paulo 14: 397-400. 
Khalil M 1938. On the history of the anti-bilharzial campaign in the Dakhla Oasis. J Egypt Med Assoc 21: 102-106.

Kinoti GK, Mumo JM 1988. Spurious human infection with Schistosoma bovis. Trans R Soc Trop Med Hyg 82: 589-590.

Leiper RT 1915. Report on the results of the bilharzia mission in Egypt, 1915. Part I. Transmission. JR Army Med Corps 25: 1-55.

McDonagh JER 1918. Antimony in bilharziasis. Lancet ii: 371

Miyairi K, Suzuki M 1914. The intermediate host of Schistosoma japonicum Katsurada. Mitt Med Fak Kaiser University Kyushu 1: 187-198.

Nunn JF, Tapp E 2000. Tropical diseases in ancient Egypt. Trans R Soc Trop Med Hyg 94: 147-153.

Pesigan TP, Hairston NG, Jauregui JJ, Garcia EG, Santos AT, Santos BC, Besa AA 1958. Studies on Schistosoma japonicum infection in the Philippines. 2. The molluscan host. Bull WHO 18: 481-578.

Picquet M, Vercruysse J, Shaw DJ, Diop M, Ly A 1998. Efficacy of praziquantel against Schistosoma mansoni in northern Senegal. Trans $R$ Soc Trop Med Hyg 92: 90-93.

Ross AGP, Sleigh AC, Li YS, Williams GM, Aligukli GDL, McManus DP 2000. Is there immunity to Schistosoma japonicum? Parasitol Today 16: 159-164.

Savioli S, Hatz C, Dixon H, Kisumku UM, Mott KE 1990. Control of morbidity due to Schis to soma haematobium on Pemba Island: egg excretion and haematuria as indicators of infection. Am JTrop Med Hyg 43: 289-295.

Stelma FF, Talla I, Sow S, Kongs M, Niang M, Polman K, Deelder AM, Gryseels B 1995. Efficacy and side effects of praziquantel in an epidemic focus of Schistosoma mansoni. Am J Trop Med Hyg 53: 167-170.

Sturrock RF, Barnish G, Upatham ES 1974. Snail findings from an experimental mollusciciding programme to control Schistosoma mansoni transmission on $\mathrm{St}$ Lucia. Int J Parasitol 4: 231-240.

Sturrock RF, Klumpp RK, Ouma JH, Butterworth AE, Fulford AJC, Kariuki HC, Thiongo FW, Koech D 1994. Observations on the effects of chemotherapy strategies on the transmission of Schistosoma mansoni in Machakos District, Kenya, measured by snail sampling and cercariometry. Parasitology 109: 443-453.

Van Etten L, Folman CC, Eggelte TA, Kremsner PG, Deelder AM 1994. Rapid diagnosis of schistosomiasis by antigen detection in urine with a reagent strip. J Clin Microbiol 32: 2404-2406.

Webbe G 1987. The use of molluscicides in the control of human trematode infections. In $\mathrm{G}$ Webbe, The Toxicology of Molluscicides, International Encyclopaedia of Pharmacology and Therapeutics, Section 125.1. Pergamon Press, Oxford, p.1-11.

Webbe G, El Hak S 1990. Progress in the control of schistosomiasis in Egypt, 1985-88. Trans R Soc Trop Med Hyg 92: 394-400.

WHO 1985. The control of schistosomiasis. Report of a WHO Expert Committee. Technical Report Series 728. WHO, Geneva, 113 pp.

WHO 1993. The control of schistosomiasis. Report of the WHO Expert Committee. Technical Report Series 830 . WHO, Geneva, 86 pp.

WHO 1998. Report of the WHO Informal Consultation on schistosomiasis control. WHO/CDS/CPC/SIP/ 99.2. WHO, Geneva, 45 pp. 
